\title{
IV. The dynamo as a generator and as a motor. Some analogies and contrasts
}

\author{
W.M. Mordey Esq.
}

To cite this article: W.M. Mordey Esq. (1886) IV. The dynamo as a generator and as a motor. Some analogies and contrasts, Philosophical Magazine Series 5, 21:128, 20-27, DOI: $10.1080 / 14786448608627804$

To link to this article: http://dx.doi.org/10.1080/14786448608627804

册 Published online: 29 Apr 2009.

Submit your article to this journal $[\pi$

Џ Article views: 2

Q View related articles $₫$ 
volt, which becomes $\left(\frac{329 \times 1 \cdot 08}{1 \cdot 114}=\right) \cdot 318$ volt, allowing for difference of standard.

In reference to a point to which these authors * drew attention a short time ago, namely, that, although the heat evolved by displacing cadmium by zinc in solutions $\cdot 25$ $\mathrm{CdCl}_{2}, 100 \mathrm{H}_{2} \mathrm{O}$ is greater than that evolved by the same substitution in the case of the sulphates, yet the E.M.F. of the zinc-cadmium chloride cell is materially less than that of the zinc-cadminm sulphate cell, my measurements afford direct confirmation, as the value given here for the average E.M.F. of the zinc-cadmium sulphate cell is -335 volt and that for the zinc-cadmium chloride cell only 301 volt, or a difference of -034 volt, substantially the same as the difference given by them, viz. $\cdot 035$.

\section{Electromotive Force of Zinc-Tin Iodide Cell.}

A cell set up with amalgamated zinc in $.25 \mathrm{ZnI}_{2}, 100 \mathrm{H}_{2} \mathrm{O}$ opposed to tin in $25 \mathrm{SnI}_{2}, 100 \mathrm{H}_{2} \mathrm{O}$, both solutions acidified with 1.5 per cent. of $\mathrm{HI}$, was found to have an E.M.F. of from $\cdot 47$ to $\cdot 49$, averaging $\cdot 485$ volt.

There being no thermal data at my disposal no comparisons can be drawn.

IV. The Dynamo as a Generator and as a Motor: Some Analogies and Contrasts. By W. M. Mordey, Esq. $\dagger$

$\mathrm{D}^{2}$ URING the last few years an immense amount of attention has been given to everything relating to theory and practice of dynamo machines. So thorough has been the study of the problems connected with these machines, which are of a character to appeal both to the physicist and the practical constructor or engineer, that it is now not difficult to lay down, in a fairly complete form, the laws governing their action, and the rules and principles under which they should be constructed; although three or four years ago much confusion and uncertainty existed as to what was best in dynamo construction.

But in electric motors the case is very different. While it is easy to name physicists and constructors in considerable

* Phil. Mag. vol. xvii. p. 378 (May 1884).

$\uparrow$ Communicated by the Author. 
numbers who hold clear and correct views on the subject of electric generators, it is by no means easy to find definite and correct explanations of what is right and what wrong in regard to the allied subject of electric motors.

And on no point does there appear to be greater uncertainty than on that of the analogies and the differences between the two machines. For instance, while it has been proved beyond question that in dynamos the most economical and best working conditions are obtained by employing field-magnets of great magnetic strength, and armatures which are relatively very weak magnetically, the only definite assertion within the writer's knowledge given with authority on this point, asserts exactly the contrary to be the case with motors, viz. that the fields should be relatively much lighter and weaker than the armatures*.

Again, what can be more striking than the great and known difference between dynamos and motors in respect to the very important matter of efficiency! Almost any modern generator will give a return in the form of electric energy of 90 per cent. of the mechanical energy expended in it, and a useful yield of over 80 per cent. in its external eircuit. In the case of the best generators this is a considerable understatement of the working conditions. With electric motors, on the other hand, one has to be contented with a much lower efficiency. The energy supplied to them is severely taxed in the process of conversion. Motors frequently yield, as mechanical energy in a useful and available form, only 30 per cent., and seldom more than 60 per cent., of the electric energy absorbed.

The reversibility of the dynamo, or its ability to work either as generator or motor, has been spoken of as one of the most important discoveries of late years (the great physicist credited with the expression of this opinion having apparently overlooked the fact that Pacinotti made his famous machine as a motor in the first place). But the fact that a given machine which will work well and efficiently as a dynamo, will not work so economically when its action is reversed and it is made to act as a motor, is a proof that the reversal is accompanied by some radical change in its action. This difference, where it is noticed at all, is generally sought to be explained by an assertion or a supposition that having been designed and made for one purpose, it was therefore not suitable for the other. No satisfactory explanation, as far as the writer is aware, has been given of the cause of this lower efficiency

" Profs. Ayrton and Perry, "Electromotors and their Government," Journ. Soc. Teleg. Eng. and Electricians, March 1883. 
of motors, or, in other words, of how the missing power is expended. In what particulars a good motor should resemble a good dynamo, and in what they should differ from one another, are also interesting questions of great importance which await answers.

The writer having, with Mr. C. Watson-who is his assistant in the works of the Anglo-American Brush Electric Light Corporation-given some attention to the matter from a practical point of view, a great necessity was felt for some foundation on which to work, similar in character to the broad general principles which serve to guide the practical constructor of dynamo machines. In the search for such general principles, all those ways of considering the actions which depend on the idea of magnetic poles in the armature were abandoned, and the conclusion was arrived at that the armature should have no polar action whatever, that the iron of the armature should have only the function of a conductor of lines of force, and that the power of the motor should be due to the simple action between the lines of force of the magnetic field and the armature-wires conveying currents at right angles to those lines of force. This mode of regarding motor action is convenient on several grounds, and leads to certain conclusions, which, if correct, form substantial bases for practical construction. Thus the armature, instead of being, as hitherto, considered as a strong electromagnet placed in the field of another electromagnet, is to have its electromagnetic functions reduced as much as possible, or preferably suppressed altogether.

The field is to be very strong.

As with such an arrangement there is no polar effect in the armature except that due to the direct magnetic induction of the field-magnets, it follows that the maximum-power is obtained with any given current when the brushes occupy an absolutely neutral position, or, in other words, when there is no "lead" and no distortion or rotation of the field. These conditions do away with the most troublesome and prolific cause of the sparking at the brushes, which is so often an objectionable feature of most electric motors.

But by working backwards in this way it was seen at once that the conditions which seemed to be best for a motor were precisely those which the would-be designer of a perfect dynamo would set before him as his goal.

Certain perfect analogies had been arrived at. In both dynamos and motors, according to this briefly sketched view :-

(1) The field should be a very strong, the armature a very weak electromagnet. 
(2) In both generators and motors "lead," distortion, or displacement of brushes or of magnetic field is wrong, and is to be avoided by attention to (1).

Whatever "lead" there may be in either case, there is this difference, that in dynamos this "lead" is in the direction of rotation; in motors it is in the opposite direction, as the course of the current through the armature is reversed, but the field is the same.

(3) In both generators and motors absence of sparking at the brushes depends mainly on the conditions of (1) being complied with.

(4) Reversal of rotation. In neither generators nor motors is movement of the brushes necessary.

But having got so far, a little consideration suggested the probable existence of another analogy. Since a dynamo having the above theoretically perfect form and action, with a constant field would produce a constant electromotive force if run at a constant speed, independently of the load or amount of current generated, a motor constructed on the same principles and having a constant field, if supplied with energy at a constant difference of potential, should run at a constant speed, independently of load.

If this should prove to be a true analogy, a simple means of obtaining results of great use in the practical application of electricity would be obtained-results which have been sought in many directions, more or less complicated, without any great success.

By permission of the Anglo-American Brush Electric light Corporation experiments were carried ont in the testing-room of their works, with a "Victoria" dynamo. The results ultimately obtained, which are given in the following tabulated account of the experiments, and in the curves plotted for them, show that this fifth analogy is as true as the preceding ones, a constancy of speed being obtained which was very remarkable -even when the load was increased, until much more than that which as a generator was usually considered the full working current was traversing the armature.

Two sets of readings were taken, working up to about the same current in each set, but with the potential-difference of the supply different in the two cases, as stated. The field was of the same strength throughout. The load consisted of another "Victoria" dynamo driven through a modified White's transmission-dynamometer, the work being varied as required by altering the external circuit of this dynamo. 
Experiments with a $D_{2}$ "Victoria" Shunt Motor at Constant E.M.F.

Difference of potential at

Speed. Current. terminals.

$$
\text { H. P.* }
$$

$\left.\begin{array}{rrcc}975 & 36 \cdot 3 & 140 & 1 \cdot 8 \\ 965 & 66 \cdot 5 & " & 6 \cdot 6 \\ 948 & 97 \cdot 1 & " & 12 \cdot 87 \\ 945 & 130 \cdot 8 & " & 16 \cdot 3\end{array}\right\} \begin{gathered}\text { Curve A. } \\ \text { Maximum speed- } \\ \text { variation 3 per } \\ \text { cent. }\end{gathered}$

$\left.\begin{array}{cccc}680 & 29 & 100 & 1 \\ 677 & 61 \cdot 4 & " & 4 \cdot 8 \\ 675 & 102 & \% & 9 \cdot 14 \\ 660 & 125 & " & 11 \cdot 7\end{array}\right\} \begin{gathered}\text { Curve B. } \\ \text { Maximum speed- } \\ \text { variation 3 per } \\ \text { cent. }\end{gathered}$

Curves connecting Speed and Work of $\mathrm{D}_{2}$ "Victoria" Shunt Motor. With supply at constant difference of potential.

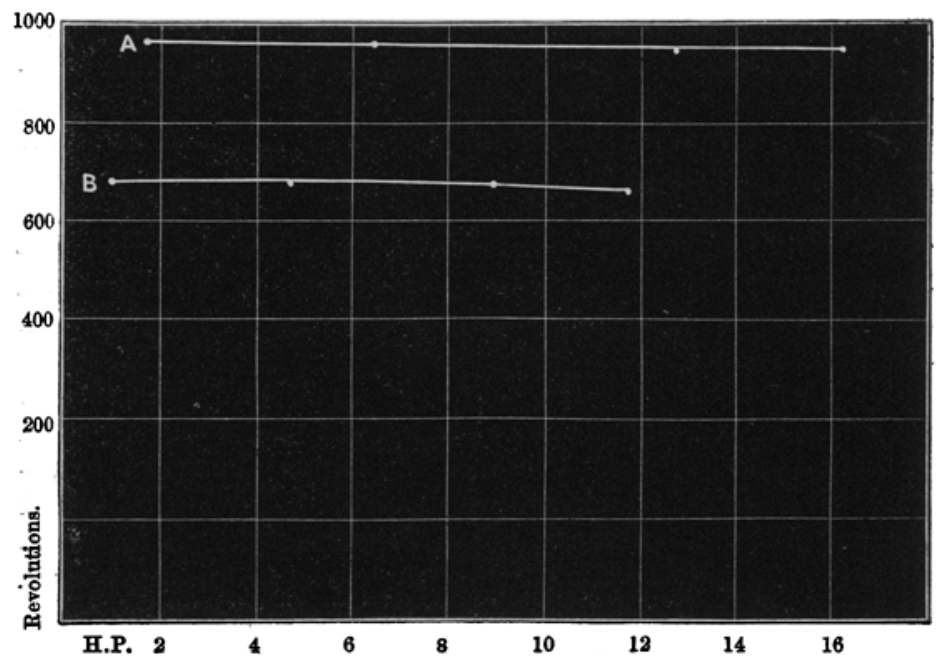

At first it appeared that the counter electromotive force of the motor was dependent neither on speed nor strength of field, as the latter was constant and the former very nearly so, while the current rose with the work; but calculation showed that this was not the case, indeed it could not be so.

Let us call the counter electromotive force $e$, and the loss of potential caused by the resistance of the armature $e_{1}$, and the difference of potential at the terminais $\mathrm{E}$. Then

$$
e+e_{1}=\mathrm{E} \text {. }
$$

* Including an unascertained loss in transmission. 
Calling the current $C$, and the resistance of the armature $R$, we know that

$$
e_{1}=\mathrm{CR} \text {; }
$$

The resistance of the armature of the motor in question was $\cdot 027 \mathrm{ohm}$, which we will call $\cdot 03$ in order to make some allowance for the effect of heating.

In the first and last readings of the second set of tests (curve B) we have therefore the following conditions :-

$\begin{array}{lrr}\text { Speed. } & e_{1 \cdot} & e . \\ 680 & \cdot 87 & 99 \cdot 13 \\ 660 & 3 \cdot 75 & 96 \cdot 25\end{array}$

Now

$$
\frac{680 \times 96 \cdot 25}{660}=99 \cdot 13 \text {. }
$$

From which it appears that the counter electromotive force was exactly proportional to the speed, as is to be expected where the field is constant and the magnetic distortion nil.

The other cases do not work out with the same accuracy. The results are, however, quite within the limits of error inseparable from the rather rough conditions of these workshop tests.

One other fact may be pointed out in connection with these tables of results and curves. In the case of dynamos working with a constant field, the output with the same current is almost exactly proportional to speed, as the E.M.F. is also simply proportional to speed. So with the motor, the speed is proportional to the E.M.F. of supply; and the work, with the same current in the two cases, is simply proportional to speed, therefore to E.M.F.

With regard to the theory alluded to above, that in a motor the fields should be much weaker and lighter than the armature, it may be pointed out that in this, as in the other points mentioned, there is a real analogy between motors and generators, inasmuch as, according to the views briefly expressed in this note, such a motor, although a bad one from most points of view, would have a certain advantage in that for its weight it would do a good deal of work. Similarly, dynamos may be, and have been built, which, although far from efficient and reliable, will give a large output for their weight. Their construction is, however, scarcely to be recommended on this ground, except, perhaps, under very exceptional circumstances; and they, as well as the motors constructed on the same lines, appear to be instances of a mistaken apprehension of elementary principles.

Having briefly traced the analogies between generators and 
motors thus far, the subject may be dismissed for the present with the remark that a further consideration of the matter serves only to reveal the fact that in almost every phase of their actions the two machines afford further opportunities of a direct comparison.

Turning now to the question of efficiency alluded to above, it is evident that there is some important cause of loss or waste of energy in electric motors which is absent in generators. This has always been a kind of lacuna in the explanations of the action of motors; and in order to localize the loss and to ascertain its cause, the several possible sources of waste were carefully considered. These are:-(a) Friction at the bearings, air-friction, and friction of the brushes against the commutator. (b) Loss of energy in heating the armature and field-conductors, and a certain loss due to self-induction. (c) Loss by the production of eddy-currents in the iron.

Now it is evident, especially with a generator or motor having the qualities sketched above, that at the same speed, and working with the same currents in its conductors, the losses under $(a)$ and $(b)$ must be identical, whether it be working as a generator or as a motor. And as with such conditions its efficiency as a motor is lower than as a generator, the cause of the loss must be sought under $(c), i$. e. the eddycurrents in a dynamo must be less than in a motor, all other conditions being the same. And such is the case, the explanation arrived at by the writer and Mr. Watson being a very simple one.

In a dynamo the rotation of the armature causes eddycurrents to be generated in the iron core, in the same direction as in the conductor proper with which the core is surrounded. Of course, as the armature is always more or less subdivided or laminated in a direction at right angles to the lines of force, any circulation of currents round the core is avoided; but local currents, which are aptly called eddies, are set up, and, taken as a whole, these eddy-currents on the outside of the core are in the same direction as the current flowing in the copper conductors.

In an electric motor, however, the eddy-currents and the currents in the copper conductor are in opposite directions; as, although the E.M.F. set up in the conductor is in the same direction in a motor as in a dynamo, the current in the former. is forced through the armature in a direction contrary to the E.M.F., or opposite to its course in a generator. According to the laws of induction, therefore, it will be seen that while in a dynamo the two sets of currents, those in the iron and those in the conductor, tend to oppose and to reduce one 
another, in a motor they act in such a manner as to mutually assist each other. Thus, with the strength of field, the current in the conductor, and the speed the same in the two cases, it will be seen that in a motor the eddy-currents in the iron core of the armatures will be greater than in a generator, and therefore the heat-loss in the former will be more than in the latter. There is little doubt that this is the cause of the lower efficiency of motors than of generators; and it points to the advisability of giving even greater attention in the former to those principles which are well understood for the reduction or elimination of eddy-currents.

V. Note on the Verification of Thermometers at the FreezingPoint of Mercury. By G. W. WhIPPLE, B.Sc., F.R.A.S., Superintendent of the Kew Observatory*.

$\mathrm{T} \mathrm{T}$ is not many years since the operation of freezing mer1 cury was considered a scientific feat, and a party of gentlemen were invited to the Kew Observatory to assist at the performance of the operation by the late Mr. R. Addams. That gentleman produced the solidified mercury by the action of ether upon carbonic acid gas in the solid form, and with his assistance considerable quantities of mercury were frozen, and a number of observations were made with carefully constructed thermometers, which gave the value for the melting-point of mercury which has since been accepted as the fixed point. Prof. Balfour Stewart communicated an account of these experiments to the Royal Society, in whose publications they will be found (Phil. Trans. 1863, pp. $425-435$ ).

Since that date the determination of the low-temperature fixed point of thermometers has become a regular operation in the verification department of the Kew Observatory, and some eight or nine dozen instruments are compared in melting mercury annually, most of them being destined for use in Canada and other cold countries.

As the mode of making this comparison is not described in any readily accessible publication, we have frequently been requested to give an account of it, and have accordingly drafted this paper with a view of putting it on record.

The carbonic acid in its liquid form is purchased generally of Orchard, of High Street, Kensington, in the well-known

* Communicated by the Physical Society : read November 14, 1885. 